\title{
Morbidity and Mortality After D2 Gastrectomy for Gastric Cancer: Results of the Italian Gastric Cancer Study Group Prospective Multicenter Surgical Study
}

\author{
By Maurizio Degiuli, Mitsuru Sasako, Antonio Ponti, Tito Soldati, Francesco Danese, and Fabio Calvo
}

\begin{abstract}
Purpose: To investigate whether pancreas preservation together with a strict quality-control system could ameliorate the outcome of D2 resections for gastric cancer in Western patients.

Patients and Methods: Italian patients with potentially curable proven adenocarcinoma of the stomach were registered from nine general and/or university hospitals in the area of Turin, Northern Italy. The study was performed according to the guidelines of the Japanese Research Society for Gastric Cancer (JRSGC). A strict quality-control system was guaranteed by a supervising surgeon of the reference center, who had stayed at the National Cancer Center Hospital, Tokyo, to learn the standard D2 gastrectomy. The standard procedure entailed removal of the level 1 and 2 lymph nodes. During total gastrectomy, the pancreas was preserved according to the Maruyama technique.
\end{abstract}

$\mathbf{J}$ APANESE INVESTIGATORS have been reporting for years successful survival data with slight morbidity and low mortality rates after extended (D2) dissection for gastric cancer. ${ }^{1}$ These radical procedures include removal of the level 2 nodes (N2) in addition to the perigastric nodes (N1). ${ }^{2}$

There has always been a reluctance by Western surgeons to adopt these more extensive procedures, due to the fear of increasing early morbidity and mortality rates. In fact, two recent European randomized controlled trials demonstrated that D2 gastrectomies are followed by higher morbidity and mortality rates than D1 resections and that these disadvantages may prove to nullify any survival benefit. 3,4

The routine adoption of distant pancreatectomy and splenectomy during total gastrectomy has been advocated as one of the reasons for the significant increase of morbidity and mortality after the more extensive procedures. ${ }^{4}$ The Italian Gastric Cancer Study Group (GCSG) was set up to determine whether pancreas preservation during total gastrectomy, together with a strict-quality control system, would ameliorate the early results of D2 resections and therefore prolong the survival of patients. We chose to conduct, at

From the Department of Oncology, Division of Surgery, Turin, Italy. Submitted November 18, 1997; accepted December 19, 1997.

Address reprint requests Maurizio Degiuli, MD, Department of Oncology, Division of Surgery, Via Cavour, 31, 10123 Turin, Italy.

c 1998 by American Society of Clinical Oncology.

0732-183X/98/1604-0022\$3.00/0
Results: Between May 1994 and December 1996, 191 eligible patients were entered onto the study. The mean number of lymph nodes removed was 39. The overall morbidity rate was $\mathbf{2 0 . 9 \%}$. Surgical complications were observed in $16.7 \%$ of patients. Reoperation was necessary in six patients and was always successful. The overall hospital mortality rate was $3.1 \%$; it was higher after total gastrectomy $(7.46 \%)$ than after distal gastrectomy $(0.8 \%)$. The average length of hospital stay was 17 days.

Conclusion: Given that postoperative morbidity and mortality rates are favorably comparable with those reported after the Western standard gastrectomy, the more extensive Japanese procedure with pancreas preservation can be regarded as a safe radical treatment of gastric cancer for selected Western patients treated in experienced centers.

Clin Oncol 16:1490-1493. (c) 1998 by American Society of Clinical Oncology.

first, a prospective one-arm multicenter trial with a strict quality-control protocol and patient selection criteria similar to those adopted in the recently published randomized trials. ${ }^{3,4}$

We now report our data on postoperative morbidity and mortality.

\section{PATIENTS AND METHODS}

\section{Registration}

Patients eligible for the trial were to have proven adenocarcinoma of the stomach that was potentially curable. Patients who required emergency procedures, had a coexisting cancer, or were older than 80 years of age were not enrolled. Also excluded were patients with severe cardiorespiratory dysfunctions that precluded more extensive dissections.

The study was directed from a central office at the reference center (Department of Oncology, Division of Surgery, Turin, Italy). Informed consent was obtained from the patients in accordance with the ethical principles adopted by each participating hospital. Data on recruitment, surgical procedures, histopathologic findings, postoperative course, and patient follow-up evaluation were collected by a surgeon at each institution and posted to a registry at the central office.

\section{Assessment of Cancer Curability}

Preoperative staging was performed to exclude clinical evidence of distant metastasis. At laparotomy, patients were to have no evidence of peritoneal and/or liver metastasis ( $\mathrm{P0}, \mathrm{H} 0$ ); no involvement of the esophagus, cardia, or duodenum; and no metastasis in paraaortic (N4) and retropancreatic nodes $(\mathrm{N} 3)$ at biopsy or in frozen sections.

\section{Treatment}

The study was performed according to the guidelines of the Japanese Research Society for Gastric Cancer (JRSGC). ${ }^{2,5}$ The standard proce- 
dure entailed removal of the level 1 and 2 nodes. Nodes of the hepatoduodenal ligament were also removed following the technique performed at the National Cancer Center Hospital, Tokyo. ${ }^{6}$ During total gastrectomy, the pancreas was preserved according to the Maruyama technique, unless it was suspected to be involved by the tumor. ${ }^{7}$

\section{Quality Control}

The Italian GCSG was set up in March 1994; eight university and/or general hospitals from Turin, Northern Italy, participated. In June 1995, a ninth hospital center joined the group. Each center had two surgeons attend all of the operations. In total, 18 surgeons participated in the trial. Before the beginning of the trial, M.D., a surgeon from the reference center, stayed at the National Cancer Center Hospital, Tokyo, to learn the D2 dissection from a specialist Japanese surgeon (M. Sasako). He was also given various didactic videos and papers taped and edited by M.S. and/or his colleagues. M.D. became the supervising surgeon of the trial. After this period, and before the trial was run, several meetings were organized among participating centers to explain the terminology, debate the proper indications, and demonstrate the technique. At least one of the two surgeons of each participating center attended the first 10 procedures in this trial, which were performed at the reference center. Afterwards, M.D. attended the first three operations performed at each center.

\section{Statistical Aspects}

Sample size calculations were performed with the intent to achieve a proportion of hospital deaths (5\%) and of postoperative complications (25\%) similar to those usually obtained with standard D1 resections. ${ }^{3,4,8}$ The target for enrollment was then set to approximately 200 patients, based on the desired level of precision in estimating the parameters of interest for the study (hospital mortality: $95 \%$ confidence interval [CI], $2.5 \%$ to $9.0 \%$; postoperative complications: $95 \% \mathrm{CI}, 19.0 \%$ to $31.5 \%$ ). CIs for percentages are based on exact binomial probabilities. The $x^{2}$ test was used to assess differences in proportions.

\section{RESULTS}

A total of 297 patients were referred to the participating centers between May 1994 and December 1996. Of these, 191 who fulfilled the eligibility criteria were entered onto the study. One hundred six patients were found to be ineligible, mostly because their disease was more extended than that required for the trial. The characteristics of eligible patients are listed in Table 1.

\section{Removal of Lymph Nodes}

Overall, the mean number of nodes removed was 39 , ranging from 22 to 93 . No center removed less than an average of 25 nodes per patient (Table 2). The median number of positive nodes, in node-positive patients, was 10 , with a range of one to 54. Table 3 lists the extent of lymph node involvement in the study population.

\section{Postoperative Hospital Morbidity}

Postoperative complications are listed in Table 4. The overall morbidity rate was $20.9 \%$ (95\% CI, $15.4 \%$ to $27.4 \%$ ). Surgical complications accounted for $16.7 \%$. Among
Table 1. Site of Tumor, Type of Gastrectomy, and Pathologic Stage

\begin{tabular}{lcc}
\hline \multicolumn{1}{c}{ Variable } & $\begin{array}{c}\text { No. of } \\
\text { Potients }\end{array}$ & $\%$ \\
\hline Eligible patients & 191 & 100 \\
Site of tumor & & \\
$\quad$ Lower third & 116 & 60.8 \\
Middle third & 52 & 27.2 \\
Upper third & 13 & 6.8 \\
Diffuse (> 2/3 of stomach) & 6 & 3.1 \\
Stump (previous resection for peptic disease) & 4 & 2.1 \\
Type of resection & & \\
Distal & 124 & 64.9 \\
Total & 67 & 35.1 \\
Japanese group staging & & \\
I (EGC) & 68 & 35.6 \\
II & 30 & 15.7 \\
III & 68 & 35.6 \\
IV & 25 & 13.1 \\
Curativity & & \\
Absolutely curative & 125 & 65.4 \\
Relatively curative, noncurative & 66 & 34.6 \\
\hline
\end{tabular}

Abbreviation: EGL, early gastric cancer.

these, anastomotic leakage was observed in 14 patients (7.1\%). Two instances of ischemic liver necrosis consequent to the ligature of the left hepatic artery in the lesser omentum were registered. Eight patients (4.1\%) had major nonsurgical complications, two of which were fatal. Six patients had a second operation, mostly because of an abdominal infection due to anastomotic leakage. All of these reoperations were successful.

\section{Postoperative Hospital Mortality}

The overall hospital mortality was six of 191 patients (3.1\%; 95\% CI, $1.2 \%$ to $6.7 \%$ ) (Table 5). Three deaths occurred due to intraabdominal infectious complications. Of the six deaths, five were observed in patients who underwent total gastrectomy and splenectomy, four of whom had disease classified as tumor-node-metastasis (TNM) stage IV because of the involvement of the hepatoduodenal ligament nodes. The hospital mortality rate was $7.46 \%$ after total gastrectomy, while it was $0.8 \%$ after distal resection $(P<.05)$.

Table 2. Number of Lymph Nodes Removed at Each Participating Center

\begin{tabular}{lcc}
\hline \multicolumn{1}{c}{ Center } & $\begin{array}{c}\text { No. of lymph } \\
\text { Nodes Removed }\end{array}$ & Range \\
\hline Calderini & 37 & $23-89$ \\
Calvo & 44 & $24-73$ \\
Capussolti & 33 & $22-53$ \\
Dellepiane & 31 & $23-68$ \\
Fronda & 41 & $22-84$ \\
Garavoglia & 25 & $24-39$ \\
Locatelli & 40 & $22-70$ \\
Mello & 50 & $24-93$ \\
Morino & 39 & $26-58$ \\
\hline
\end{tabular}


Table 3. Lymph Node Involvement

\begin{tabular}{lccccc}
\hline & \multicolumn{2}{c}{ Overall $[N=191]$} & & \multicolumn{2}{c}{$E G C(N=68)$} \\
\cline { 2 - 3 } \cline { 6 - 6 } Involvement & No. & $\%$ & & No. & $\%$ \\
\hline pNO & 78 & 35.4 & 54 & 79.4 \\
pN+ & 113 & 64.6 & & 14 & 20.6 \\
pN1 & 41 & 21.5 & 8 & 11.8 \\
pN2 & 56 & 29.3 & 5 & 7.3 \\
pN3* & 16 & 8.4 & 1 & 1.5 \\
\hline
\end{tabular}

"Involvement of location no. 12 lymph nodes (lymph nodes of the hepatoduodenal ligament\}.

\section{Postoperative Hospital Stay}

The mean length of hospital stay was 17 days (range, 7 to 61).

\section{DISCUSSION}

Over the years, Japanese investigators have shown beneficial survival effects with low morbidity and mortality rates less than $3 \%$ after extensive dissections for gastric cancer. ${ }^{9}$ The main reasons for the successful Japanese results are technical skills and strict respect to the treatment schedule; actually, in Japan, D2 resection is a common practice in ordinary general hospitals.

In Western centers, extensive procedures are not common because of the fear of increasing early morbidity and mortality. ${ }^{10}$ Although low morbidity and mortality rates have also been reported in the West (mostly in retrospective studies), ${ }^{11,12}$ two main recent prospective randomized trials found that D2 resections are associated with a higher morbidity and mortality rate than D1 procedures. ${ }^{3,4}$ Subset analysis of these trials has demonstrated that the increase of

Table 4. Types of Complications

\begin{tabular}{lcc}
\hline \multicolumn{1}{c}{ Surgical Complications } & $\begin{array}{c}\text { No. of } \\
\text { Patients }\end{array}$ & $\%$ \\
\hline Anastomotic leakage (esophagojejunal) & 7 & 3.6 \\
Anastomotic leakage (gastrojejunal) & 3 & 1.5 \\
Duadenal stump leakage & 4 & 2.0 \\
Colonic perforation & 1 & 0.5 \\
Acute pancreatitis and gallbladder perforation & 1 & 0.5 \\
Pancreatic fistula & 1 & 0.5 \\
Anastomotic bleeding & 2 & 1.0 \\
Ischemic liver necrosis* & 2 & 1.0 \\
Anastomotic edema & 3 & 1.5 \\
Laparocele & 1 & 0.5 \\
Intestinal occlusion & 2 & 1.0 \\
Peritonitis & 3 & 1.5 \\
Jejunal torsion & 1 & 0.5 \\
Total non-surgical complications & 32 & 16.7 \\
Cardiac & 2 & 1.0 \\
Pulmonary & 5 & 2.6 \\
Thromboembolic & 5 & 0.5 \\
Total & 1 & 4.1 \\
Total complications & 8 & 20.9 \\
\hline *One patient developed abdominal infection & &
\end{tabular}

*One patient developed abdominal infection.
Table 5. Postoperative Mortality: 6 Patients (3.1\%)

\begin{tabular}{cccl}
\hline $\begin{array}{c}\text { Age of } \\
\text { Patients } \\
\text { lyears) }\end{array}$ & Stage & \multicolumn{1}{c}{$\begin{array}{c}\text { Type of } \\
\text { Gastrectomy }\end{array}$} & \multicolumn{1}{c}{ Cause of Death } \\
\hline 68 & IIIA & Total & \multicolumn{1}{c}{ Liver necrosis and abdominal infection } \\
69 & IA & Distal & Myocardial infarction \\
74 & IV & Total & Esophagojejunal leakage \\
89 & IV & Total & Duodenal stump leakage \\
69 & IV & Total & Pleuric empyema \\
70 & IV & Total & Stroke \\
\hline
\end{tabular}

morbidity in the D2 arm is largely due to distal pancreatic resection and splenectomy, which have been performed routinely during total gastrectomy. ${ }^{4}$ The unfavorable postoperative outcome reported may prove to nullify any survival benefit of extensive procedures in Medical Research Council (MRC) and Dutch patients.

Our study was designed to test the feasibility and safeness of the extensive procedure if performed with a strict quality-control system and if total gastrectomy with D2 dissection is performed without distal pancreatectomy, unless pancreas involvement is suspected. The lymph nodes along the splenic artery (no. 11) were removed following the technique described by Maruyama et al. ${ }^{7}$

We have previously reported our interim analysis of morbidity and mortality in the first 118 patients treated with D2 dissection; hospital mortality and postoperative morbidity rates were $2.5 \%$ and $20.3 \%$, respectively. ${ }^{13}$ Actually, the overall postoperative morbidity rate is $20.9 \%$; the rate of anastomotic and duodenal stump leakage is $7.1 \%$, while the rate of nonsurgical complications is only $4.1 \%$. The overall postoperative mortality rate is $3.1 \%$. Of six deaths, five occurred in patients submitted to total gastrectomy and splenectomy; of these five patients, four had stage IV disease (due to the involvement of location no. 12 lymph nodes). Our final results show that hospital mortality and postoperative morbidity after D2 dissection with pancreas preservation can be kept at levels comparable to those achieved after standard D1 dissection in Western series ${ }^{8,10}$ and in the control arms of the recently published randomized trials. ${ }^{3,4}$ The rates of anastomotic leakages were similar in all of these trials, whereas intraabdominal infection and pancreatic leakage rates, as well as the nonsurgical morbidity rate, were lower in the present study. The mortality rate after anastomotic leakage is approximately $15 \%$, which is close to that observed in Japan and lower than that reported by Bonenkamp et al. ${ }^{3}$ The mortality rate was higher after total than after distal gastrectomy in the present series, although the pancreas was routinely preserved; this seems to suggest a further adverse effect of splenectomy on early outcome, as recently described by various investigators at second World Congress of the International Gastric Cancer Association, in Munich, Germany. ${ }^{14,15}$ On the other hand, the mortality rate 
after distal gastrectomy is 0.8 , which is close to that reported by Japanese investigators. These data may prove to support our study protocol, mostly as regards the quality control. Patient selection is not likely to be the reason for our low morbidity and mortality rates. Characteristics of recruited cases are indeed similar to the study population of the Dutch and British randomized trials. A further reason for our sucessful outcome could be the number of patients operated on at each institution. Apart from the ninth center, which joined the GCSG a year after the study was started, each participating center treated at least 15 patients, and five of them treated more than 25 . In every center, each patient was always treated by the same two operating surgeons, who attended each operation together. Since the learning curve has been recently suggested by Parikh et al $^{16}$ to last for 15 to 25 procedures, each center should consequently have acquired sufficient experience and technical skill. Given that postoperative morbidity and mortality are comparable if not better than those reported after the Western standard technique,,$^{3,4,8,9}$ the more extensive procedure with preservation of the pancreas can be regarded as a safe radical treatment of gastric cancer for Western patients in experienced centers. Moreover, it can be performed in controlled trials to assess its efficacy on survival without the adverse effect of an unfavorable early outcome. We are planning to run a new randomized controlled three-arm trial to compare the early outcome and survival of standard D1 gastrectomy with the more extensive pancreas-preserving D2 procedure with and without splenectomy.

\section{ACKNOWLEDGMENT}

We thank Dr Tiziano Allone for assistance with data collection and processing, and the pathologists who took part in this work.

\section{APPENDIX}

The following are members of the Gastric Cancer Study Group: T. Allone, F. Danese, F. Calvo, M. Degiuli, R. Bussone, and P. Calderini (Oncology Department), M. Morino (Department of Surgery, University of Turin), M. Garavoglia and F. Olivieri (Department of Surgery, University of Novara), G.R. Fronda and T. Soldati (Department of Surgery, Ospedale SG Battista), M. Dellepiane and A. Balcet (Department of Surgery, Ospedale Gradenigo), L. Capussotti and M. Calgaro (Department of Surgery, Ospedale Mauriziano), L. Locatelli and D. Scaglione (Department of Surgery, Ospedale Valdese), P. Mello Teggia and D. Andreone (Department of Surgery, Ospedale San Luigi, Orbassano, Torino).

\section{REFERENCES}

1. Maruyama K, Sasako M, Kinoshita T, et al: Effectiveness of systematic lymph node dissection in gastric cancer surgery, in Nishi $\mathrm{M}$, Ichikawa H, Nakajima T, et al (eds): Gastric Cancer. Hong Kong, Springer-Verlag, 1993, pp 293-305

2. Japanese Research Society of Gastric Cancer: The general rules for the gastric cancer study in surgery and pathology. Part I. Clinical classification. Jpn J Surg 11:127-139, 1981

3. Bonenkamp JJ, Songun I, Hermans J, et al: Randomised comparison of morbidity after D1 and D2 dissection for gastric cancer in 996 Dutch patients. Lancet 345:745-748, 1995

4. Cuschieri A, Fayers P, Fielding J, et al: Postoperative morbidity and mortality after $R 1$ and $R 2$ resection for gastric cancer: Results of the MRC surgical trial. Lancet 347:995-999, 1996

5. Japanese Research Society of Gastric Cancer: The general rules for the gastric cancer study in surgery and pathology. Part II. Histological classification of gastric cancer. Jpn J Surg 11:140-145, 1981

6. Sasako M: Radical surgery, in Sugimura T, Sasako M (eds): Gastric Cancer. Oxford, United Kingdom, Oxford University, 1997, pp 223-248

7. Maruyama K, Sasako M, Kinoshita T, et al: Pancreas preserving total gastrectomy for proximal gastric cancer. World J Surg 19:532-536, 1995

8. Gouzi JL, Huguier M, Fagniez PL, et al: Gastrectomie totale contre gastrectomie partielle pour adeno-cancer de l'antre. Une etude Francaise prospective controlée. Ann Chir 43:356-360, 1989

9. Kinoshita T, Maruyama K, Sasako M, et al: Treatment results of gastric cancer patients: Japanese experience, in Nishi M, Ichikawa $H$, Nakajima T, et al: Gastric Cancer. Hong Kong, Springer-Verlag, 1993, pp 319-331
10. Wanebo HJ, Kennedy BJ, Chmiel J, et al: Cancer of the stomach. A patient care study by the American College of Surgeons. Am J Surg 218:583-592, 1993

11. Sue-Lin H, Johnston D, Martin IG, et al: Gastric cancer: A curable disease in Britain. BMJ 307:591-595, 1993

12. Smith JW, Shiu MH, Kelsey L, et al: Morbidity of radical lymphadenectomy in the curative resection of gastric carcinoma. Arch Surg 126:1469-1473, 1991

13. Degiuli M, Sasako M, Ponzetto A, et al: Extended lymph-node dissection for gastric cancer. Interim results of a prospective multicenter analysis of morbidity and mortality in 118 consecutive cases. Eur J Surg Oncol 23:310-314, 1997

14. Wanebo HJ, Kennedy BJ, Winchester DP, et al: Role of splenectomy in gastric cancer surgery. Adverse effect of elective splenectomy on long-term survival, in Siewert JR, Roder JD (eds): Progress in Gastric Cancer Research 1997. Proceedings of the Second International Gastric Cancer Congress. Munich, Germany, April 27-30, 1997. Bologna, Italy, Monduzzi Editore, 1997, pp 979-982

15. Kama NA, Avsar FM, Doganay M, et al: Effect of splenectomy on morbidity and survival following gastrectomy for gastric adenocarcinoma, in Siewert JR, Roder JD (eds): Progress in Gastric Cancer Research 1997. Proceedings of the Second International Gastric Cancer Congress. Munich, Germany, April 27-30, 1997. Bologna, Italy, Monduzzi Editore, 1997, pp 983-986

16. Parikh D, Johnson M, Chagla L, et al: D2 gastrectomy: Lessons from a prospective audit of the learning curve. Br J Surg 83:1595-1599, 1996 